\title{
A profile of pornography users in Australia: findings from the Second Australian Study of Health and Relationships
}

\begin{abstract}
There are societal concerns that looking at pornography has adverse consequences among those exposed. However, looking at sexually explicit material could have educative and relationship benefits. This paper identifies factors associated with looking at pornography ever or within the last 12 months for men and women in Australia, and the extent to which reporting an 'addiction' to pornography is associated with reported bad effects.
\end{abstract}

Data from the Second Australian Study of Health Relationships were used: computer-assisted telephone interviews completed by a representative sample of 9,963 men and 10,131 women aged 1669 years from all Australian states and territories, with an overall participation rate of $66 \%$.

Most men (84\%) and half of the women (54\%) had ever looked at pornographic material. Threequarters of these men (76\%) and over one-third of these women (41\%) had looked at pornographic material in the past year. Very few respondents reported that they were addicted to pornography (men $4 \%$ and women $1 \%$ ), and of those who said they were addicted, about half also reported that using pornography had had a bad effect on them.

Looking at pornographic material appears to be reasonably common in Australia, with adverse effects reported by a small minority. 


\section{Introduction}

Pornography has been defined as "printed or visual material containing the explicit description or display of sexual organs or activity, intended to stimulate sexual excitement".(1) However, what constitutes sexual activity and excitement can be open to interpretation in different cultures and societies,(2) and what is considered culturally or socially acceptable can change over time. For example, the difference between pornography and erotica (literature or other art dealing with romantic sex) can be difficult to distinguish, with some commentators opting for a commonsense understanding of pornography: that it is whatever we think of as pornographic in everyday life.(3)

From a consumer's perspective, pornography may not have much significance beyond how it is used. People most commonly use pornography as an aid for masturbation or an aid for sexual interaction with a partner.(4) At the time of its use, people appear not to give consideration to ideological or moral debates about pornographic material, however there may be feelings of guilt or shame associated with masturbation and/or pornography use depending on religious or cultural teachings.(5) Grubbs et al. found a positive relationship between religiosity and perceived 'addiction' to pornography and that this relationship was mediated by moral disapproval of pornography use.(6)

For many years researchers have explored possible negative effects of pornography (especially violent or degrading pornography), with a particular focus on aggression, violence and the objectification of women. $(7,8)$ Some researchers see pornography as engendering a culture of violence against women.(9) More recently these views have been challenged, with Ferguson and Hartley disagreeing with the hypothesis that pornography contributes to increased sexual assault behavior and "may actually provide a catharsis to alleviate sexual aggression" (p 328).(10) They and others $(11,12)$ have noted that data from the United States demonstrate an inverse relationship between pornography consumption and rape rates, which has also been observed in other countries.(13) Posner theorizes that if pornography is a complement to masturbation and consensual sex, then consumption of pornography could also reduce rape rates.(14) However, these ecological data (pornography consumption and rape rates) do not provide evidence of causality.

Other commentators see pornography as contributing to the sexualization of society, and through easy access via the internet, potentially influencing negatively the development of children's and adolescents' sexuality. There is widespread agreement on restricting exposure of young children to pornography, and while there are similar concerns for exposure of adolescents these concerns do not acknowledge possible sexual education benefits.(15)

Among men, (greater) use of pornography has been linked to erectile dysfunction, decreased sexual desire or orgasmic difficulties, and unrealistic expectations about women and sex.(16) However, there 
has been criticism of some of the early research on the effects of pornography on men, including a lack of methodological rigour (including cross-sectional non-causal data) and a concern that it may have been ideologically driven by conservative religious or business interests. $(17,18)$ Recent research has found little evidence of an association between pornography use and male sexual health disturbances. $(19,20)$ However, some men may be more susceptible than others to negative outcomes from interacting with more extreme types of pornography that are violent towards women.(21)

There are also many other questions that could be asked about the effects of pornography, with the possibility that non-violent sexually explicit materials may have positive effects. Does consuming pornography lead people to talk more openly about sex? Does it lead to the creation of a stronger sense of sexual agency? Does it lead to more satisfying sex lives? Positive effects associated with pornography use include general sexual education for young adults about anatomy, sexual positions and practices,(22) sexual education for some subgroups (such as young gay men) that might not have access to information specifically relevant to them (for example, safe anal sex)(23) and more gender egalitarian attitudes than non-users.(24)

An Australian survey of pornography users found $58 \%$ of respondents thought pornography had had a very positive or a positive effect on their attitudes towards sexuality; $35 \%$ felt it had had no effect; and $7 \%$ thought it had a negative effect or a large negative effect.(25) The main positive effects included: feeling less repressed about sex; feeling more open-minded about sex; increased tolerance of other people's sexualities; giving pleasure to consumers; providing educational insights; sustaining sexual interest in long-term relationships; making consumers more attentive to a partner's sexual desires; helping consumers find an identity or community; and helping them to talk to their partners about sex. The most common negative effects were that pornography: led consumers to objectify people; caused them to have unrealistic sexual expectations; caused relationship problems; caused loss of interest in sex; and led to addiction.(25) However, the combination of self-reported data and self-selection by survey participants with a very low response rate raises the question of how representative this sample was of all Australians.

In the Second Australian Study of Health and Relationships (ASHR2), a large representative sample national telephone survey of sexual attitudes and behaviour, more than two-fifths of respondents (men, 63\%; women, 20\%) said they had looked at pornography in any medium in the past year, with men three times as likely as women to look at pornography.(26) This appears to have gone up dramatically over the last decade, although a direct comparison with the first Australian Study of Health and Relationships (ASHR1) is not possible, where respondents were asked if they had 'gone to a sex site on the internet on purpose' (17\% of men and 2\% of women).(27) There is some evidence from the Australian Longitudinal Study of Health and Relationships that there has been an increase in 
the proportions of men visiting internet sex sites (up from $14 \%$ in the first year to $22 \%$ in the fourth year), with no corresponding change among women (2\% in year 1 and year 4).(28) However, there was has been a decrease in watching X-rated films (from 36\% down to 19\% among men; from 13\% down to $9 \%$ among men), which may reflect broader changes in technology usage.(28)

Given the reported increases in use of pornography, it is of interest to understand at a population level who is using pornography, and the extent to which users report 'addiction' or bad effects. Available evidence suggests that compared to non-users, pornography users tend to be male, younger, have positive attitudes towards teenage sex and more sexual partners,(29-31) and be less likely to be religious.(6) Psychological distress may be associated with pornography use in some population groups.(6) Less is known about associations between pornography use and other demographic factors, such as income, occupation and ethnicity, nor with other factors such as sexual identity, specific sexual practices (e.g., anal sex) sometimes depicted in pornography, or other health risk behaviors such as alcohol consumption.

The data collected for ASHR2 provide an opportunity to address the following research questions:

- What are the socio-demographic and selected behavioural factors associated with having looked at pornography ever or within the last 12 months for men and women in Australia?

- To what extent is reporting an addiction to pornography associated with reported bad effects from pornography?

- What factors are associated with reporting addiction to pornography and bad effects from pornography?

\section{Methods}

The methodology used in the Second Australian Study of Health Relationships (ASHR2) is described in detail elsewhere.(32) Briefly, between October 2012 and November 2013, computer-assisted telephone interviews were completed by a representative sample of 20,094 Australian residents aged 16-69 years from all states and territories. Ethical approval was obtained from the researchers' host universities, and all participants were old enough to give informed consent (32+). Respondents were selected using dual-frame modified random-digit dialling (RDD), combining directory-assisted, landline-based RDD with RDD of mobile telephones. The overall response rate (participation rate among eligible people) was $66.2 \%$.

To maximise the number of interviews with people who had engaged in less-common and/or morerisky behaviours, all respondents who had had no sexual partners in the previous year, who had had more than one partner in the previous year, and/or who reported homosexual experience completed a 
long form of the survey instrument, which collected detailed data on their sexual attitudes, relationships and behaviours. Most respondents reported having had one partner in the previous year and no homosexual experience: $20 \%$ of these respondents were randomly selected to complete the long-form interview, and the other $80 \%$ completed a short-form interview. As a consequence, 8,577 completed the long-form interview, and 11,517 completed the short-form interview. Answers to questions that occurred only in the long-form interview are reported after weighting to reflect the sample as a whole.

The questions relating to use of, and beliefs about pornography were presented in the long-form interview. Respondents were asked "Have you ever looked at pornographic material?" and if so, "And have you looked at it in the last 12 months?" If respondents wanted to clarify what was considered pornography, the scripted interviewer response was "This includes magazines, pictures, cards, films, books and material on the internet."

Respondents used a 5-point scale (Strongly agree/Agree/Neither/Disagree/Strongly disagree) to indicate the extent of their agreement with three statements about pornography: "Pornography degrades the women shown in it", "Pornography degrades the men shown in it", "Pornography can improve sexual relations among adults";(33) and three novel statements: "Pornography can enhance pleasure of masturbation", "You feel using porn has had a bad effect on you" and "You feel you are addicted to pornography". These questions were only asked of people who completed a long-form interview. The questions on enhancing the pleasure of masturbation, perceived pornography addiction and personal bad effect were only asked of those respondents who had ever looked at pornography. Responses to attitude items were dichotomised so that those who gave "agree" or "strongly agree" responses were compared to all other respondents.

Correlates of the main outcomes examined in this paper (exposure to pornography, attitudes toward pornography, and perceived addiction to pornography and "bad effect") included a range of demographic characteristics. Respondents' ages were recoded into six groups: 16-19, 20-29, 30-39, 40-49, 50-59 and 60-69 years. Language spoken at home was recoded as English or a language other than English. Sexual identity (in answer to the question 'Do you think of yourself as ...') was coded as heterosexual, homosexual, or bisexual; too few respondents stated that they were 'queer', 'other', or 'undecided' to allow analysis of these groups. Respondents' reported highest completed level of education was recoded to distinguish between those who had not (yet) completed secondary school, those who had completed secondary school, and those who had completed post-secondary education. Respondents indicated whether they had a particular religious belief or faith. Respondents' postcodes were recoded to determine whether respondents lived in a major city, a regional area, or a remote area (i.e. areas with relatively unrestricted, restricted, and very restricted access to goods, services and 
opportunities for social interaction, respectively).(34) To approximate the gross annual household income quintiles reported by the Australian Bureau of Statistics for 2009-10,(35) respondents' reported annual income was grouped into five categories: less than $\$ 28,000, \$ 28001-\$ 52,000$, $\$ 52$ 001-\$83,000, \$83 001-\$125,000 and more than $\$ 125,000$. Respondents' reported occupation was coded into the nine major categories of the Australian Standard Classification of Occupations,(36) and then recoded to distinguish between managerial/professional occupations, white-collar occupations and blue-collar occupations.

Sexual behaviours included in this analysis included number of sexual partners in the past year,(37) masturbation in the past year,(26) first vaginal intercourse before age 16 years,(38) whether the respondent had ever had heterosexual anal sex, and current relationship status.(37)

Reponses to questions about frequency and volume of alcohol consumption were used to determine whether respondents exceeded National Health \& Medical Research Council guidelines for moderate alcohol consumption at the time of the first Australian Study of Health \& Relationships (ASHR1) i.e., 28 standard drinks (each $10 \mathrm{~g}$ or $12.5 \mathrm{~mL}$ of pure ethyl alcohol) per week for men and 14 for women.(39)

Psychological distress was measured by the Kessler-6 psychological distress scale. Respondents used a 5-point scale (all of the time / most of the time / some of the time / a little of the time / none of the time) to indicate their experience of depressive and anxious symptoms over the previous month.(40) To maintain consistency with the distress scale used in ASHR1, the word 'depressed' in the item 'How often have you felt so depressed that nothing could cheer you up?' was replaced with 'sad'. As in ASHR1, a score of 1 standard deviation above the mean was used as a marker of elevated psychosocial distress.(41)

Data were weighted to adjust for the probability of each respondent being selected for a landline or mobile phone interview, a long-form interview, and (for landline participants) the number of in-scope adults in the household. Data were then weighted to match the Australian population on the basis of age, gender, area of residence (i.e. state by ARIA category) and telephone ownership (i.e. mobile telephone only vs other), resulting in an adjusted sample of 10056 men and 10038 women (total 20 094). The data were thus weighted to account for the specifics of our sample design and the fact that particular types of people were slightly over- or under-represented. Therefore, the data presented are representative of the Australian population aged 16-69 years.(32)

Weighted data were analysed using the survey estimation commands in Stata Version 13.1.(42) Data were analysed descriptively using univariate logistic regression for dichotomous outcomes. To 
identify factors significantly associated with exposure to pornography (ever and in the last year) and perceived addiction to pornography and "bad effects" adjusting for other variables in the model, a manual multivariable model selection was undertaken with backward elimination. For each model, initially all variables were entered into the model. Then one by one variables with the smallest Wald chi-square were removed, checking the effect of each removed variable on the overall model. Criteria for inclusion in the base model were: a 10\% change in the estimate of effect (odds ratio), then a material difference in the precision (i.e. change in standard error); lastly, significant variables that did not confound or affect precision could be removed from the base model. Odds ratios (OR) and adjusted odds ratios (AOR - adjusting for all other significant bivariate correlates) with 95\% confidence intervals $(\mathrm{CI})$ were calculated as a measure of the likelihood of change.

\section{Results}

Most men (84\%) and about one in two women (54\%) reported that they had ever looked at pornographic material, with three-quarters of these men having looked at pornographic material in the past year (76\%), and over one-third of these women having looked at pornographic material in the past year (41\%) (see Tables 1 and 2). For men, being older than 50 years was associated with a lower likelihood of ever having looked at pornography, as was speaking a language other than English at home, having a religion or faith, or living in with a regular partner. Univariate factors associated with an increased likelihood of men ever having looked at pornography included identifying as gay/homosexual or bisexual, having a household income over $\$ 83,000$ per annum, having two or more sexual partners in the past year, masturbating in the past year, having had vaginal intercourse before age 16, ever having had heterosexual anal intercourse, exceeding NHMRC guidelines for alcohol consumption and reporting elevated psychological distress. However, after adjustment for other variables in a multivariable model and removing those variables not significantly influencing the model, having a high income (over $\$ 125,000$ per annum), having two or more sexual partners in the past year, and having masturbated in the past year were the only factors significantly associated with men having ever looked at pornography.

Men were less likely to have looked at pornography in the past year if they were aged 40 years or more, had a religion or faith, lived in a regional centre and had a live-in regular sexual partner. They were more likely to have looked at pornography in the past year if they identified as gay/homosexual or bisexual, had a secondary school education, had a household income over $\$ 125,000$ per annum, had two or more sexual partners in the past year, had masturbated in the past year, had had vaginal intercourse before age 16, had ever had heterosexual anal intercourse, or exceeded the NHMRC guidelines for alcohol consumption. After adjustment for other variables in the model, for men, identifying as homosexual, having two or more sexual partners in the past year, having masturbated in the past year and ever having had anal intercourse were significantly associated with having looked at 
pornography in the past year, and older age (60-69 years) was significantly associated with being less likely to have looked at pornography in the past year.

For women, being aged less than 20 or over 60 years, speaking a language other than English and having a religion or faith were associated with a lower likelihood of having ever looked at pornography. Factors associated with increased likelihood of women ever having looked at pornography were identifying as lesbian or bisexual, having post-secondary education, having one or more sexual partners in the past year, masturbating in the past year, having had vaginal intercourse before age 16, ever having had heterosexual anal intercourse, exceeding NHMRC guidelines for alcohol consumption and reporting elevated psychological distress. However, after adjustment for other variables in a multivariable model and removing those variables not significantly influencing the model, being over 30 years and having a religion or faith were significantly associated with a lower likelihood of ever having looked at pornography, and having masturbated in the past year and ever having had anal intercourse were significantly associated with having ever looked at pornography.

There was a lower likelihood of having looked at pornography in the past year for women over 30 years, living in a regional area, having a religion or faith, and living with a regular partner. Factors associated with increased likelihood of having looked at pornography in the past year were identifying as lesbian or bisexual, having secondary or post-secondary school education, having a non-live-in regular sexual partner, having one or more sexual partners in the past year, having masturbated in the past year, having had vaginal intercourse before age 16 and ever having had heterosexual anal intercourse. However, after adjustment for other variables in a multivariable model and removing those variables not significantly influencing the model, being over 30 years and having a religion or faith were significantly associated with a lower likelihood of having looked at pornography in the past year. Having one or more sexual partners in the past year, having masturbated in the past year and ever having had anal intercourse were significantly associated with having looked at pornography in the past year.

Most respondents (men 90\% and women 79\%) agreed or strongly agreed that pornography could enhance the pleasure of masturbation. For most of the attitude statements about pornography, men gave significantly more positive responses than did women (see Table 3). The exception was for agreement with the statement that 'using porn had a bad effect on you', which was only asked of respondents who had ever looked at pornography: there was little sex difference. Among respondents who had ever looked at pornography, most disagreed that using pornography had had a bad effect on them (men $82 \%$ and women $84 \%$ ). Very few respondents reported that they felt addicted to pornography (men $4 \%$ and women $1 \%$ ). 
An equal proportion of men agreed and disagreed that pornography degraded the women shown in it, with women more likely than men to agree that it degraded the women shown in it (see Table 3). Fewer men and women agreed that pornography degraded the men shown in it. Two thirds of men $(66 \%)$ and half of women (54\%) agreed that pornography could improve sexual relations among adults. While very few men or women agreed with the statement that they felt addicted to pornography, about half of men and women who did so also reported that using pornography had had a bad effect on them (see Table 4).

Among those people who had ever looked at pornography, being a manager/professional was associated with a lower likelihood of self-reported addiction to pornography at a bivariate level (see Table 5). A greater likelihood of reporting being addicted to pornography was associated with being male, 16-19 or 30-39 years of age, living in a remote region, having two or more sexual partners in the past year, ever having had heterosexual anal intercourse and reporting higher psychological distress. However, after adjustment for other variables in a multivariable model and removing those variables not significantly influencing the model, being male, ever having had anal intercourse and psychological distress were the only factors significantly associated with a higher likelihood of selfreported addition to pornography.

Being older than 40 years, having a live-in-partner, having one sexual partner in the past year, having had first vaginal intercourse before age 16 years, and drinking in excess of NHMRC guidelines were associated with a lower likelihood of reporting that pornography had had a bad effect at a bivariate level (see Table 5). Factors associated with a higher likelihood of reporting that pornography had had a bad effect were speaking English at home, having a religion or faith, and reporting elevated psychological distress. After adjustment for other variables in a multivariable model and removing those variables not significantly influencing the model, being older than 40 years and drinking in excess of NHMRC guidelines were associated with a lower likelihood of reporting pornography had had a bad effect, while having a religion or faith was significantly associated with a higher likelihood of reporting that pornography had had a bad effect.

\section{Discussion}

For men, there was a clear consistency of factors associated with reporting they had ever looked at pornography or looked at it in the past year. This was also evident but not quite so obvious for women. Although women were less likely than men to have looked at pornography, for both men and women there was a pattern of association with looking at pornography and greater sexual experience or proclivity (more partners, masturbation, anal sex experience) compared with respondents less likely to use pornography (older, having a religion). Adjusting for other variables in multi-variable models 
dramatically reduced the number of factors that significantly affected the model, but they highlight that having had anal sex, more recent sexual partners and recent masturbation for both men and women were associated with ever having looked at pornography and having looked at it in the past year. This is consistent with other research that found that for both Internet pornography and general pornography use there were links with greater numbers of sexual partners.(31)

At a uni-variable level, both men and women were less likely to have looked at pornography in the past year if they had a regular live-in relationship, suggesting that their sexual needs were being met to some extent or that those with a live-in partner may not use pornography due to partner disapproval of pornography. However, this association was no longer significant when other variables were introduced into the model. For both men and women having two more partners in the past year was associated with a higher likelihood of looking at pornography in the last year, perhaps related to wanting to satisfy sexual needs.

Ever having had heterosexual anal intercourse was strongly associated with lifetime and past year viewing of pornography, and reporting feeling addicted to pornography, for both men and women after adjustment for other variables in the models. This has not been reported previously. However, it cannot be determined if viewing pornography leads to heterosexual anal sex (because it features regularly in some pornography), or if anal sex experience is a proxy for sexual adventourism that also manifests itself through viewing sexually explicit material.

Very few respondents who had looked at pornography agreed with the statement that they were addicted to pornography. Given the prominence of public debates about the addictive nature of pornography, the data suggests that there is a mismatch between journalistic concerns about the genre and the experiences of consumers. Among those respondents who did nominate an addictive relationship only about half agreed that pornography had had a bad effect on them, which raises a question about what they meant by 'addicted' or how respondents interpreted the word 'addicted' in this context.

Casual exposure to pornography would not be considered any kind of psychological disorder, although obsessive use that interfered with one's health, wellbeing or responsibilities might. The debate in the literature about whether a hypersexual disorder exists as a mental disorder appears to have resolved in the negative, with American Psychiatric Association ultimately rejecting it from inclusion in the Diagnostic and Statistical Manual of Mental Disorders, Fifth Edition (DSM-5), due largely to a lack of empirical evidence. $(18,43)$ An addiction model may not be the best way to understand using pornography. 
Overall, a substantial minority of respondents (12\%) did report a bad effect from pornography, slightly higher than the 7\% reported by McKee in 2007.(25) Younger people had higher rates of reporting a bad effect from pornography and this finding deserves greater exploration. It is possible that these bad effects could include guilt, given that there is an increasing use of anti-pornography discourses in educational materials, which risk inculcating self-hatred in young people who consume pornography.(44) Even though those people with a religion or faith were less likely to have looked at pornography in the past year, those that did had a four-and-a-half times greater odds of reporting bad effects. Possible internal conflict between religious beliefs and sexual interests may contribute to the adverse perception.(45) The role of religion and religious instruction in relation to pornography addiction and adverse effects bears further study. The majority of respondents reported benefits from pornography, such as enhanced pleasure when masturbating or improving adult sexual relations.

\section{Limitations / Strengths}

This study is unique in being able to describe the use of pornography in a large representative sample of Australian adults. It was able to identify limited self-reported impacts of pornography use, but due to the cross-sectional nature of the data we cannot attribute causality between any of the variables, such as elevated psychological distress and reporting bad effects from pornography. We were unable to establish whether exposure to sexually explicit material led to engagement in sexual behaviour or whether those individuals who were more sexually adventurous also had a tendency to seek out sexually explicit material.(46) We did not ask about negative impacts of pornography on other people or relationships, and the self-reported measures used of "bad effects" and "addiction" are very subjective. Furthermore, within the broad-focus of the ASHR2 questionnaire, it was only possible to ask brief questions about use of pornography, which serve better as indicators of behaviour than complex measures of behaviour.

We did not measure levels of pornography consumption, nor what type of pornography was being viewed. There is a difference between what is available and what is being consumed and the effects will vary according to the pornography consumed; for example, if the sex act focuses on inequalities of status or agency between participants, or shows a lack of sexual reciprocity, the effects will clearly be different.(8)

Despite some limitations to the level of detailed information that were gathered in ASHR2, the data from this population-representative study make an incremental contribution to current knowledge derived from convenience samples. They indicate that looking at pornographic material is quite common in Australia, with adverse effects reported by a small minority. 


\section{Conflicts of interest}

None declared.

\section{References}

1. Oxford Dictionaries. Pornography 2016 [cited 201619 January]. Available from:

http://www.oxforddictionaries.com/definition/english/pornography.

2. Hyde HM. A History of Pornography. London: Heinemen; 1964.

3. Williams L. Hardcore: Power, Pleasure and the Frenzy of the Visible. Berkeley: University of California Press; 1989.

4. Ullén M. Pornography and its critical reception: toward a theory of masturbation. 2009; No.

51. http://www.ejumpcut.org/archive/jc51.2009/UllenPorn/index.html 2009 [cited 201619 January]. Available from: http://www.ejumpcut.org/archive/jc51.2009/UllenPorn/index.html.

5. Patterson R, Price J. Pornography, religion, and the happiness gap: Does pornography impact the actively religious differently? Journal for the Scientific Study of Religion. 2012;51:79.

6. Grubbs JB, Exline JJ, Pargament KI, Hook JN, Carlisle RD. Transgression as addiction: religiosity and moral disapproval as predictors of perceived addiction to pornography. . Arch Sex Behav. 2015;44:125-36.

7. Hald GM, Malamuth NM. Self-perceived effects of pornography consumption. Arch Sex Behav. 2008;37(4):614-25.

8. McKee A. The objectification of women in mainstream pornographic videos in Australia. J Sex Res. 2005;42(4):277-90.

9. Ellis K, O'Dair B, Tallmer A. Feminism and pornography. Feminist Review. 1990;36:15-8.

10. Ferguson $\mathrm{CJ}$, Hartley RD. The pleasure is momentary...the expense damnable? The influence of pornography on rape and sexual assault. Aggression and Violent Behavior. 2009;14(5):323-9.

11. D'Amato A. Porn up, rape down. . 2006.

12. Kendall TD. Pornography, rape, and the internet (doc). Retrieved 22 December 2014. Fourth bi-annual Conference on the Economics of the Software and Internet Industries; January 19-20, 2007; Toulouse, France2007.

13. Diamond M. Pornography, public acceptance and sex related crime: A review. International Journal of Law and Psychiatry. 2009;32(5):304-14.

14. Posner RA. Sex and Reason. Cambridge, MA: Harvard University Press.; 1994.

15. Ybarra ML, Mitchell KJ. Exposure to internet pornography among children and adolescents: a national survey. Cyberpsychology, Behavior and Social Networking. 2005;8(5):473-86.

16. Paul P. Pornified: How pornography is transforming our lives, our relationships, and our families. New York: Time Books; 2005.

17. Short M, Black L, Smith AH, Wetterneck C, Wells DE. A review of Internet pornography use research: Methodology and content from the past 10 years. Cyberpsychology, Behavior, and Social Networking. 2012;15(1):13-23.

18. Ley D, Prause N, Finn P. The emperor has no clothes: a review of the 'pornography addiction' model. Current Sexual Health Reports in press.

19. Landripet I, Stulhofer A. Is pornography use associated with sexual difficulties and dysfunctions among younger heterosexual men? J Sex Med. 2015;12(5):1136-9.

20. Prause N, Pfaus J. Viewing Sexual Stimuli Associated with Greater Sexual Responsiveness, Not Erectile Dysfunction. Sexual medicine. 2015;3(2):90-8.

21. Twohig M, Crosby J, Cox J. Viewing Internet pornography: For whom is it problematic, how, and why? Sexual Addiction and Compulsivity. 2009;16:253-66. 
22. McKee A. 'Saying You've been at Dad's Porn Book is Part of Growing Up': Youth, Pornography and Education. 2007; 155: 116-122. Metro Magazine. 2007;155:116-22.

23. Kubicek K, Beyer WJ, Weiss G, Iverson E, Kipke MD. In the dark: young men's stories of sexual initiation in the absence of relevant sexual health information. Health Education and Behaviour 2009;37(2):243-63.

24. Kohut T, Baer JL, Watts B. Is pornography really about "Making Hate to Women"? Pornography users hold more gender egalitarian attitudes than nonusers in a representative American sample. The Journal of Sex Research. 2015; (online first).

25. McKee A. Positive and negative effects of pornography as attributed by consumers. Australian Journal of Communication. 2007;34(1):87-104.

26. Richters J, de Visser R, Badcock P, Smith A, Rissel C, Simpson J, et al. Masturbation, paying for sex, and other sexual activities: the Second Australian Study of Health and Relationships. Sexual health. 2014;11(5):461-71.

27. Richters J, Grulich AE, de Visser RO, Smith AM, Rissel CE. Sex in Australia: autoerotic, esoteric and other sexual practices engaged in by a representative sample of adults. Aust N Z J Public Health. 2003;27(2):180-90.

28. Richters J, Heywood W, Shelley J, Pitts M, Smith AMA, editors. Do women really like sex? Evidence from the Australian Longitudinal Study of Health and Relationships. 7th Australian Women's Health Conference, May8-10 2013; Sydney.

29. Poulsen FO, Busby DM, Galovan AM. Pornography use: who uses it and how it is associated with couple outcomes. J Sex Research. 2013;50(1):72-83.

30. Wright PJ. U.S. Males and Pornography, 1973-2010: Consumption, predictors, correlates. The Journal of Sex Research 2013;50(1):60-71.

31. Harkness EL, Mullan BM, Blaszczynski A. Association between pornography use and sexual risk behaviors in adult consumers: a systematic review. Cyberpsychol Behav Soc Network. 2015;18(2):59-71.

32. Richters J, Badcock P, Simpson J, Shellard D, Rissel C, de Visser R, et al. Design and methods of the Second Australian Study of Health and Relationships. Sexual health. 2014;11(5):383-96.

32+ National Health \& Medical Research Council (2015) National Statement on Ethical Conduct in Human Research (2007) (Updated May 2015). available at: www.nhmrc.gov.au/book/nationalstatement-ethical-conduct-human-research. last visited 05 April 2016

33. de Visser RO, Badcock PB, Simpson JM, Grulich AE, Smith AMA, Richters J, et al. Attitudes toward sex and relationships: the Second Australian Study of Health and Relationships. Sexual health. 2014;11(5):397-405.

34. Commonwealth Department of Health and Aged Care. Measuring Remoteness: Accessibility/ Remoteness Index of Australia (ARIA). Canberra: Commonwealth Department of Health and Aged Care, 2001.

35. Australian Bureau of Statistics. Household income and income distribution, Australia 2009-

10. ABS Catalogue Number 6523.0. Canberra: Australian Bureau of Statistics; 2011.

36. Australian Bureau of Statistics. Australian Standard Classification of Occupations, Second Edition. ABS Catalogue No. 1220.0. Canberra: Australian Bureau of Statistics, 1997.

37. Badcock PB, Smith AMA, Richters J, Rissel C, de Visser RO, Simpson JM, et al. Characteristics of heterosexual regular relationships among a representative sample of adults: the Second Australian Study of Health and Relationships. Sexual health. 2014;11(5):427-38.

38. Rissel C, Heywood W, de Visser RO, Simpson JM, Grulich AE, Badcock PB, et al. First vaginal intercourse and oral sex among a representative sample of Australian adults: the Second Australian Study of Health and Relationships. Sexual health. 2014;11(5):406-15.

39. National Health and Medical Research Council (NHMRC). Australian alcohol guidelines: health risks and benefits. Canberra: NHMRC, 2001. 
40. Kessler RC, Andrews G, Colpe L, Hiripi E, Mroczek DK, Normand SL, et al. Short screening scales to monitor population prevalences and trends in non-specific psychological distress.

Psychological medicine. 2002;32(6):959-76.

41. de Visser RO, Rissel CE, Richters J, Smith AM. The impact of sexual coercion on psychological, physical, and sexual well-being in a representative sample of Australian women. Arch Sex Behav. 2007;36(5):676-86.

42. StataCorp. Stata Statistical software: Release13.1. . College Station, TXTexas: StataCorp LP; 2014.

43. Reid RC, Kafka MP. Controversies about hypersexual disorder and the DSM-5. Current Sexual Health Reports. 2014;6:259-64.

44. McKee A. The pornography consumer as 'Other'. In: Clarissa Smith C, Attwood F, McNair B, Egan D, editors. The Routledge Companion to Media, Sex and Sexuality. London: Routledge; in press. p. TBC.

45. de Visser RO, Smith AM, Richters J, Rissel CE. Associations between religiosity and sexuality in a representative sample of Australian adults. Arch Sex Behav. 2007;36(1):33-46.

46. Braun-Courville D, Rojas M. Exposure to sexually explicit websites and adolescent sexual attitudes and behaviors. Journal of Adolescent Health. 2009;45(2):156-62. 
